\title{
Arthroplasty of the Knee
}

National Cancer Institute

\section{Source}

National Cancer Institute. Arthroplasty of the Knee. NCI Thesaurus. Code C51563.

Surgical reconstruction or replacement of all or part of a damaged knee joint with an artificial joint or artificial components. 